\title{
El proyecto multimedia del Instituto Francés de Estudios Andinos (IFEA)
}

\section{Hugues Sicard}

\section{(2) OpenEdition \\ 1 Journals}

Edición electrónica

URL: http://journals.openedition.org/bifea/4824

DOI: $10.4000 /$ bifea.4824

ISSN: 2076-5827

Editor

Institut Français d'Études Andines

\section{Edición impresa}

Fecha de publicación: 1 abril 2006

Paginación: 89-90

ISSN: 0303-7495

\section{Referencia electrónica}

Hugues Sicard, «El proyecto multimedia del Instituto Francés de Estudios Andinos (IFEA) », Bulletin de I'Institut français d'études andines [En línea], 35 (1) | 2006, Publicado el 08 abril 2006, consultado el 02 diciembre 2020. URL : http://journals.openedition.org/bifea/4824 ; DOI : https://doi.org/10.4000/bifea. 4824

\section{(c) $(7)(9$}

Les contenus du Bulletin de l'Institut français d'études andines sont mis à disposition selon les termes de la licence Creative Commons Attribution - Pas d'Utilisation Commerciale - Pas de Modification 4.0 International. 


\section{EL PROYECTO MULTIMEDIA DEL INSTITUTO FRANCÉS DE ESTUDIOS ANDINOS (IFEA)}

El IFEA inició en 2001 un proyecto de catálogo documentario multimedia sobre las tradiciones orales y musicales de los Países Andinos orientado hacia dos direcciones:

- La salvaguardia de las colecciones grabadas en el marco de la investigación francesa.

- El apoyo de los centros de archivos andinos de los países andinos en sus esfuerzos para salvaguardar los archivos sonoros y audiovisuales etnográficos.

\section{Creación del CASAE en 2003}

En diciembre de 2003, el IFEA y el Instituto Colombiano de Antropología e Historia (ICANH) organizaron en Bogotá un primer seminario sobre la salvaguardia de los documentos sonoros etnográficos.

Los participantes pudieron constatar la vulnerabilidad de los centros representados y la falta de coordinación sobre los asuntos discutidos. Para fortalecer las instituciones, compartir las experiencias y coordinar la búsqueda de recursos, los participantes del seminario decidieron conjuntamente crear el Comité operativo de censo y valoración de Archivos Sonoros y Audiovisuales Etnográficos de los países andinos (CASAE. Véase http://casae.org para más detalles y consultar los estatutos).

\section{Presentación del seminario del CASAE en Cusco, 19-22 de abril 2006}

Después de los seminarios de Bogotá $(2003 ; 2004)$ y de La Paz (2005), el CASAE organizó un nuevo seminario en la ciudad de Cusco gracias a la colaboración del CBC y a la cooperación francesa, siguiendo con los trabajos iniciados en La Paz, 2005, a propósito de la catalogación y de la digitalización de los archivos.

Asistieron 35 personas representando a 20 instituciones (Bolivia: 6; Colombia: 3; Ecuador:1; Perú: 7; Venezuela: 1) que participan activamente de la conservación de los rasgos documentales de las tradiciones orales y musicales de los países andinos (bibliotecas nacionales, universidades, escuelas o institutos de folklore, museos).

Evento tras evento, el compromiso individual e institucional se refuerza, incluso al nivel financiero y a pesar que el programa era muy denso, hubo una participación muy activa y las evaluaciones anónimas del seminario hechas por los participantes demostraron el éxito del evento.

\section{Conclusiones}

Los principales elementos de conclusión fueron los siguientes:

- Consolidar el CASAE vía la puesta en marcha de un sistema Internet colaborativo («wiki») de creación de documentación técnica y una lista de difusión.

- Difundir vía página web casae.org extractos sonoros de los centros de archivos para ilustrar las descripciones de las colecciones.

- Seguir los trabajos de adaptación para la zona andina de la guía Guide d'analyse documentaire du son inédit (publicación para el final de 2006 por la Biblioteca Nacional de Colombia y el 
Instituto Francés de Estudios Andinos).

- Ver las posibilidades de organizar el siguiente evento en la ciudad de Quito durante el II Congreso de Antropología y Arquelogía ecuatorianas en octubre de 2006.

Hugues SICARD 